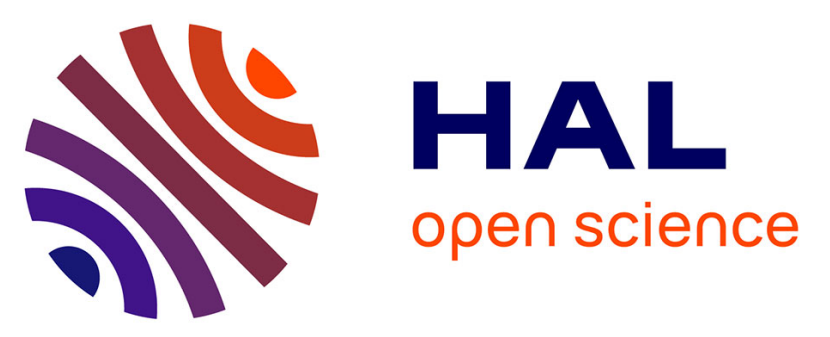

\title{
Activation of human pro-urokinase by unrelated proteases secreted by Pseudomonas aeruginosa
}

Nathalie Beaufort, Paulina Seweryn, Sophie de Bentzmann, Aihua Tang, Josef Kellermann, Nicolai Grebenchtchikov, Manfred Schmitt, Christian P. Sommerhoff, Dominique Pidard, Viktor Magdolen

\section{- To cite this version:}

Nathalie Beaufort, Paulina Seweryn, Sophie de Bentzmann, Aihua Tang, Josef Kellermann, et al.. Activation of human pro-urokinase by unrelated proteases secreted by Pseudomonas aeruginosa: LasB and protease IV activate human pro-urokinase. Biochemical Journal, 2010, 428 (3), pp.473-482. 10.1042/BJ20091806 . hal-00486859

\section{HAL Id: hal-00486859 https://hal.science/hal-00486859}

Submitted on 27 May 2010

HAL is a multi-disciplinary open access archive for the deposit and dissemination of scientific research documents, whether they are published or not. The documents may come from teaching and research institutions in France or abroad, or from public or private research centers.
L'archive ouverte pluridisciplinaire HAL, est destinée au dépôt et à la diffusion de documents scientifiques de niveau recherche, publiés ou non, émanant des établissements d'enseignement et de recherche français ou étrangers, des laboratoires publics ou privés. 


\section{ACTIVATION OF HUMAN PRO-UROKINASE BY UNRELATED PROTEASES SECRETED BY PSEUDOMONAS AERUGINOSA}

Nathalie Beaufort ${ }^{*}, \dagger, 1$, Paulina Seweryn ${ }^{*}$, Sophie de Bentzmann ${ }^{*}$, Aihua Tang ${ }^{\S}$, Josef Kellermann", Nicolai Grebenchtchikov"l, Manfred Schmitt ${ }^{\text {"I }}$, Christian P. Sommerhoff ${ }^{\ddagger}$, Dominique Pidard ${ }^{\dagger}$, Viktor Magdolen ${ }^{*}$

*Department of Obstetrics and Gynecology, Technical University of Munich, Ismaninger Str. 22, D-81675 Munich, Germany;

${ }^{\dagger}$ INSERM, U698, Univ Paris 7-Denis Diderot, 46 rue H. Huchard, 75015 Paris, France;

${ }^{+}$Sensing environment and community lifestyle in Pseudomonas aeruginosa, CNRS LISM (UPR9027)-Aix-Marseille Université, 31 Chemin Joseph Aiguier, 13402 Marseille Cedex 20, France;

${ }^{\S}$ Department of Microbiology, University of Mississippi Medical Center, 2500 North State St., Jackson, MS 39216, USA;

${ }^{11}$ Max-Planck-Institute of Biochemistry, Am Klopferspitz 18, D-82152 Martinsried, Germany; II Department of Laboratory Medicine, Radboud University Nijmegen Medical Centre, PO Box 9101, 6500 HB Nijmegen,The Netherlands;

${ }^{\ddagger}$ Department of Clinical Chemistry and Clinical Biochemistry, Ludwig-MaximiliansUniversity, Nußbaumstr. 20, D-80336 Munich, Germany

Running Title: LasB and protease IV activate human pro-urokinase

Key words: Pseudomonas aeruginosa, LasB, protease IV, human urokinase, plasminogen activation system, bacterial invasion

\section{Footnotes}

${ }^{1}$ To whom correspondence should be addressed: Nathalie Beaufort, INSERM U698, Hôpital X. Bichat, 46 rue H. Huchard, 75015 Paris, France; Tel: (33)140258600; Fax: (33)140258602; E-mail: nbeaufortgbb@yahoo.fr

Abbreviations: uPA, urokinase-type plasminogen activator; uPAR, uPA receptor; Plg, plasminogen; Pm, plasmin; PAI-1, plasminogen activator inhibitor type-1; MMP, matrix metalloproteinase; PIV, protease IV 


\section{SYNOPSIS}

Pathogenic bacteria, including Pseudomonas aeruginosa, interact with and engage the host plasminogen (Plg) activation system, which encompasses the urokinase(uPA)-type Plg activator, and is involved in extracellular proteolysis, including matrilysis and fibrinolysis. We hypothesized that secreted bacterial proteases might contribute to the activation of this major extracellular proteolytic system, thereby participating in bacterial dissemination.

We report that LasB, a thermolysin-like metalloprotease secreted by $P$. aeruginosa, converts the human uPA zymogen into its active form $\left(\mathrm{k}_{\mathrm{cat}}=4.9 \mathrm{~s}^{-1}, \mathrm{~K}_{\mathrm{m}}=8.9 \mu \mathrm{M}\right)$. Accordingly, while the extracellular secretome from the LasB-expressing, pseudomonal strain PAO1 efficiently activates pro-uPA, the secretome from the isogenic LasB-deficient strain PDO240 is markedly less potent in pro-uPA activation. Still, both secretomes induce some metalloprotease-independent activation of the human zymogen. The latter involves a serine protease, which we identified via both recombinant protein expression in E. coli and purification from pseudomonal cultures, as protease IV (PIV; $\mathrm{k}_{\mathrm{cat}}=0.73 \mathrm{~s}^{-1}, \mathrm{~K}_{\mathrm{m}}=6.2 \mu \mathrm{M}$ ). In contrast, neither secretomes, nor the pure proteases activate Plg. Along with this, LasB converts Plg into mini-Plg and angiostatin, while, as previously reported, it processes the uPA receptor, inactivates the plasminogen activator inhibitor 1 , and activates pro-matrix metalloproteinase 2. PIV does not target these factors at all.

To conclude, LasB and PIV, although belonging to different protease families and displaying quite different substrate specificities, both activate the urokinase-type precursor of the Plg activation cascade. Direct pro-uPA activation, as also reported for other bacterial proteases, might be a frequent phenomenon that contributes to bacterial virulence. 


\section{INTRODUCTION}

Proteases are present in all living organisms. In mammals, these enzymes are involved in a multitude of (patho)physiological processes, both intracellularly, such as protein quality control or apoptotic cell death, and extracellularly, such as complement system activation, coagulation and fibrinolysis, inflammation, as well as normal cell migration or malignant tumor cell invasion [1]. Microorganisms, including pathogenic bacteria, also produce proteases, which primarily provide free amino acids and/or participate to house keeping functions [2-4]. Interestingly, some of these proteases also regulate the transition from an adhesive to an invasive bacterial phenotype, dampen the host innate and acquired defenses, and/or damage host tissues [3-6]. Accordingly, a number of microbial proteases have been reported, and in some cases demonstrated, as significant virulence factors $[2-4,6]$.

One of the host multicomponent systems that is affected by bacterial proteases is the plasminogen activation system [7-9]. This major fibrinolytic/matrilytic and inflammatory system is composed of the serine (Ser-) protease plasmin (Pm), its precursor plasminogen (Plg), the urokinase-type (uPA) and tissue-type (tPA) proteolytic activators of Plg, as well as the serpin-type protease inhibitors $\alpha_{2}$-antiplasmin and plasminogen activator inhibitor type-1 (PAI-1) [10-12]. Numerous pathogenic bacteria actually interact with this host system through either or both (i) binding of Plg via surface-exposed, lysine-rich residues, (ii) production of Plg-activating factors, either displaying proteolytic activity (e.g., the outer membrane aspartic protease Pla from Yersinia pestis), or functioning as nonproteolytic activators (e.g., the wellcharacterized staphylo- or strepto-kinase) and furthermore, (iii) expression of proteases which degrade host serpins [2, 7-9]. Altogether, these host/pathogen interactions induce dysregulated engagement of the Plg activation system and are thus thought to promote host tissue destruction and bacterial dissemination and invasion, which led to the concept of "bacterial metastasis", by analogy to the uPA/Pm-driven progression of invasive cancer cells [2, 7-9]. In line with this, we recently demonstrated that aureolysin, a thermolysin-like metalloprotease secreted by the Gram-positive bacterium Staphylococcus aureus, does not only disrupt the host protease inhibitor network by degrading $\alpha_{2}$-antiplasmin and PAI-1, but also activates the host protease zymogen pro-uPA [13].

Considering that other pathogenic prokaryotes might hijack this major mammalian proteolytic system via direct pro-uPA activation as well, we investigated the capacity of proteases secreted by Pseudomonas aeruginosa to do so. $P$. aeruginosa is a wide-spread opportunistic human pathogen, which can provoke local (e.g., from the skin, wounds, as well as respiratory and urinary tracts) to systemic, benign to life-threatening infections [14]. Along with this, this Gram-negative bacterium, which produces biofilms and displays a high capacity to develop resistance to antibiotics, is a frequent cause for nosocomial infections [14]. Among the secreted pseudomonal factors, there is an array of proteases, including the metalloproteases LasA, LasB (pseudolysin) and alkaline protease (AprA), as well as the Ser-protease protease IV (PIV/PrpL) $[4,15,16]$. In addition with these proteases, a high and a low molecular mass, Ser-proteases $(\mathrm{LepA}, \approx 100 \mathrm{kDa}$, and PASP, $\approx 18.5 \mathrm{kDa}$, respectively) have recently been identified in the pseudomonal secretome [17-19]. LasB, which is also one of the major secreted pseudomonal proteins, is expressed to high levels both in vitro and in vivo, and is an acknowledged virulence factor in lung and skin infection models [16]. This $33 \mathrm{kDa}$ protein belongs to the thermolysin/M4 family of metalloproteases and accordingly, it shares sequence and structure homologies with staphylococcal aureolysin [20, 21]. LasB, thus, appeared as a good candidate to display a direct pro-uPA activating capacity.

Using purified or recombinant bacterial proteases, as well as pseudomonal extracellular secretomes, we demonstrate that LasB and PIV, although being unrelated proteases, both target and activate human pro-uPA, while leaving Plg proteolytically inactive. This pathway is likely to contribute to bacterial invasion [22]. Moreover, whereas LasB processes a number 
of components of the Plg system including Plg itself, the uPA receptor, its inhibitor PAI-1, as well as one major Pm target, the pro-matrix metalloproteinase-2 (pro-MMP-2), PIV does not target any of these proteins. 


\section{EXPERIMENTAL \\ Material}

Purified and recombinant proteins. Purified LasB $(0.5 \mathrm{mg} / \mathrm{ml}, \approx 15 \mu \mathrm{M})$ isolated from a pathogenic strain of $P$. aeruginosa was from Elastin Products Company (Owensville, MO, USA) and had a specific activity of $260 \mathrm{U} / \mathrm{mg}$ protein. Native PIV $(0.085 \mathrm{mg} / \mathrm{ml}, \approx 3.2 \mu \mathrm{M})$ was purified from the extracellular medium of pseudomonal cultures, as reported by Engel and co-workers [23]. Recombinant human pro-uPA $(1 \mathrm{mg} / \mathrm{ml}, \approx 20 \mu \mathrm{M})$ expressed in Escherichia coli, was a kind gift from A.G. Saunders (Grünenthal, Aachen, Germany). Human Glu-Plg $(2 \mathrm{mg} / \mathrm{ml}, \approx 20 \mu \mathrm{M})$ and $\mathrm{Pm}(1 \mathrm{mg} / \mathrm{ml}, \approx 10 \mu \mathrm{M}, 4.6 \mathrm{U} / \mathrm{mg})$, purified from plasma, were from Sigma-Aldrich (Saint-Louis, MO, USA). Human active uPA ( $1 \mathrm{mg} / \mathrm{ml}, \approx$ $20 \mu \mathrm{M}, 100,000 \mathrm{IU} / \mathrm{mg}$ ), purified from urine, was from ProSpec-Tany TechnoGene (Rehovot, Israel). Human recombinant $\mathrm{uPA}$ receptor ( $\mathrm{uPAR}, 0.5 \mathrm{mg} / \mathrm{ml}, \approx 10 \mu \mathrm{M}$ ), encompassing the residues 1-281 fused to a carboxyterminal His-tag, was from R\&D Systems (Minneapolis, MI, USA). Recombinant human PAI-1 $(10 \mu \mathrm{g} / \mathrm{ml}, \approx 0.2 \mu \mathrm{M})$ was from Hyphen Biomed (Neuville-sur-Oise, France).

Antibodies. A chicken polyclonal antibody $(\mathrm{Ab})$ directed to human $\mathrm{uPA}$ and strongly reacting with the A-chain of the protease has been produced in-house [24], a mouse monoclonal Ab directed to uPAR domain 2 (\#3932, reacting with amino acids 125-132 [25]) was from American Diagnostica (Greenwich, CT, USA), a mouse monoclonal Ab directed to PAI-1 (C9, reacting with amino acids 24-158) was from Santa Cruz Biotechnologies (Santa Cruz, CA, USA), and a mouse monoclonal Ab directed to poly-histidine was from Qiagen (Penta-His, Hilden, Germany). Horseradish peroxidase (HRP-) conjugated Abs against chicken or mouse Ig were from Sigma-Aldrich and from Jackson ImmunoResearch (West Grove, PA, USA), respectively.

\section{Bacterial strains and preparation of bacterial extracellular secretomes}

The P. aeruginosa, LasB-producing strain PAO1 [26] and the strain PAO1lasB9 (referred to as PDO240), in which the lasB gene sequence has been deleted and replaced with a spectinomycin resistance cassette [27], were used in this study. Bacteria were grown overnight at $37^{\circ} \mathrm{C}$ with shaking in Luria broth liquid medium, until cells had reached the stationary growth phase. Bacterium-free culture supernatants were then obtained by a first centrifugation at $6,000 \mathrm{~g}$, followed by a second one at $12,000 \mathrm{~g}$, both for $10 \mathrm{~min}$. Supernatants were further filtered through $0.22 \mu \mathrm{m}$ membranes to provide the conditioned growth media, which contain the array of bacterial factors secreted under these experimental conditions, including proteases, and are thereafter referred to as the bacterial secretomes, PAO1-Sec and PDO240-Sec, respectively. These milieus were immediately frozen in aliquots and stored at $80^{\circ} \mathrm{C}$.

\section{Cloning, expression and purification of recombinant PIV}

The coding sequence of mature PIV (amino acids 212-462; Swiss-Prot Accession Number Q9HWK6) was amplified by nested PCR, and 5' and 3' extensions harboring appropriate restriction sites (BamHI, HindIII) for cloning were added by additional PCRs. The PCR fragment was then inserted into the bacterial expression vector pQE-30 (Qiagen). The resulting fusion gene encodes mature PIV preceded by an N-terminal extension of 17 amino acids including the (His) ${ }_{6}$-tag.

Overnight cultures of transformed XL1 Blue cells (Stratagene, La Jolla, CA, USA) were diluted and grown at $37^{\circ} \mathrm{C}$ with vigorous shaking in 2 XTY medium to an optical density of 0.7 , then induced with $1.5 \mathrm{mM}$ isopropyl $\beta$-D-1-thiogalactopyranoside and cultured for 3 additional hours. After centrifugation, the bacterial pellet was frozen at $-20^{\circ} \mathrm{C}$. Cells were lyzed in $6 \mathrm{M}$ guanidine hydrochloride, $10 \mathrm{mM}$ Tris- $\mathrm{Cl}, 100 \mathrm{mM} \mathrm{NaH} \mathrm{PO}_{4}, 8 \mathrm{mM} 2-$ 
mercaptoethanol, $\mathrm{pH} 8.0$ on a rotating wheel for $2 \mathrm{~h}$ at $4^{\circ} \mathrm{C}$. The lysate was then centrifuged at $10,000 \mathrm{~g}$ for $10 \mathrm{~min}$, the supernatant collected and the $\mathrm{pH}$ adjusted to 8.0.

Thereafter, (His) $6_{6}$-tagged PIV was purified via affinity chromatography using a Ni-NTA Superflow resin (Qiagen) under denaturing conditions in two subsequent steps. First, proteins were washed and eluted by a $\mathrm{pH}$ gradient: starting off with $6 \mathrm{M}$ guanidine hydrochloride, 10 $\mathrm{mM}$ Tris, $100 \mathrm{mM} \mathrm{NaH} \mathrm{PO}_{4}, 8 \mathrm{mM}$ 2-mercaptoethanol, $\mathrm{pH} 8.0$, the column was further washed with $8 \mathrm{M}$ urea, $10 \mathrm{mM}$ Tris, $100 \mathrm{mM} \mathrm{NaH} \mathrm{PO}_{4}, 8 \mathrm{mM}$ 2-mercaptoethanol, $\mathrm{pH} 8.0$, 7.0, 6.0, and 5.3, respectively. Most of the bound recombinant PIV was finally eluted with the same buffer at $\mathrm{pH}$ 4.0. In the second purification step, an imidazol concentration gradient was used. For binding of PIV, the $\mathrm{pH}$ of the eluate of the first column was adjusted to 8.0 and the column loaded in the presence of $5 \mathrm{mM}$ imidazol. Subsequently, the column was washed with $8 \mathrm{M}$ urea, $10 \mathrm{mM}$ Tris, $100 \mathrm{mM} \mathrm{NaH} \mathrm{PO}_{4}, 8 \mathrm{mM}$ 2-mercaptoethanol, $\mathrm{pH} 8.0$ containing increasing concentrations of imidazol: 5, 10, 20, 30 and $40 \mathrm{mM}$. Finally, PIV was eluted with the same buffer containing $200 \mathrm{mM}$ imidazol.

Prior to refolding, purified PIV was incubated overnight at $20^{\circ} \mathrm{C}$ in the elution buffer containing $10 \mathrm{mM}$ DTT and then dialyzed overnight in a Spectra/Por membrane (cut-off: 10 $\mathrm{kDa}$ ) against an 100-fold volume of $4 \mathrm{M}$ urea, $50 \mathrm{mM}$ Tris- $\mathrm{HCl}, 100 \mathrm{mM} \mathrm{NaCl}, 0.005 \%$ Tween-20, pH 8.0. Refolding of PIV was performed in $2 \mathrm{M}$ urea, $50 \mathrm{mM}$ Tris- $\mathrm{HCl}, 100 \mathrm{mM}$ $\mathrm{NaCl}, 2.2 \mathrm{mM} \mathrm{MgCl}$, $50 \mathrm{mM}$ glycine, $5 \mathrm{mM}$ reduced glutathione, $0.5 \mathrm{mM}$ oxidized glutathione (GSH:GSSG ratio 10:1), 0.005\% Tween-20, $\mathrm{pH} 8.0$, in an 100-fold volume of the sample at $4{ }^{\circ} \mathrm{C}$ for $10 \mathrm{~h}$ and subsequently in an 100-fold sample volume of the same buffer containing $1 \mathrm{M}$ urea at $4{ }^{\circ} \mathrm{C}$ for $72 \mathrm{~h}$. The refolding buffer was then exchanged with $100 \mathrm{mM}$ $\mathrm{NaCl}, 50 \mathrm{mM}$ Tris-HCl, $0.005 \%$ Tween-20, $\mathrm{pH} 8.0$, incubated for $12 \mathrm{~h}$, and changed twice. Finally, the protein solution was cleared by centrifugation at $12,000 \mathrm{~g}$ and the purified protein stored in this buffer at $-20^{\circ} \mathrm{C}$. The protein concentration of recombinant PIV was estimated to $10 \mu \mathrm{g} / \mathrm{ml}(\approx 0.4 \mu \mathrm{M})$, as determined on Coomassie-stained gels calibrated with the Page-Ruler unstained Protein Ladder from Fermentas Life Sciences $(0.2 \mathrm{mg} / \mathrm{ml}$ of each protein, Helsingbord, Sweden).

As a control, an irrelevant (His) ${ }_{6}$-tagged protein (the uPA receptor domain 1 , uPAR $_{1-94}$, thereafter referred to as uPAR-D1; [25]) was expressed, purified and refolded using a similar procedure as for recombinant PIV.

\section{Exposure of purified pro-uPA, Plg, uPAR and PAI-1 to pseudomonal proteases}

Pro-uPA (200 ng for immunoblot analysis and activity measurement, $5 \mu \mathrm{g}$ for aminoterminal microsequencing), Plg (200 ng for activity measurement, $1 \mu \mathrm{g}$ for Coomassie blue staining and $5 \mu \mathrm{g}$ for aminoterminal microsequencing), uPAR (20 ng) or PAI-1 (200 ng) were adjusted to a $20 \mu \mathrm{l}$ final volume in $100 \mathrm{mM}$ Tris, $100 \mathrm{mM} \mathrm{NaCl}, \mathrm{pH} 7.5$ (Tris/ $\mathrm{NaCl}$ ). Proteins were either left untreated for $1 \mathrm{~h}$ at $37^{\circ} \mathrm{C}$, or exposed (i) to the respective activators of pro-uPA and $\mathrm{Plg}, \mathrm{Pm}(45 \mathrm{nM})$ and $\mathrm{PPA}(90 \mathrm{nM})$, (ii) to purified LasB in the range $1-100 \mathrm{nM}$, (iii) to recombinant PIV in the range $7.5-200 \mathrm{nM}$, or to $200 \mathrm{nM}$ recombinant uPAR-D1, as negative control, (iv) to $100 \mathrm{nM}$ native PIV, or (v) to PAO1-Sec or PDO240-Sec diluted in the range 0.04 to $1 \%(\mathrm{v} / \mathrm{v})$ in Tris/NaCl. Some assays were performed in the presence of various combinations of the following selective protease inhibitors (Sigma-Aldrich), at the indicated finale concentration: 1,10-phenanthroline (OPA), $10 \mathrm{mM}$; benzamidine, $5 \mathrm{mM}$; transepoxysuccinyl-L-leucylamido-(4-guanidino)butane (E-64), $10 \mu \mathrm{M}$; pepstatin A, $5 \mu \mathrm{M}$. After incubation, samples were cooled on ice, and frozen before further analysis (see below).

\section{Exposure of fibroblast-derived human pro-MMP-2 to pseudomonal proteases}

Human myofibroblasts were isolated from surgically resected stenotic calcified cardiac valves as previously reported [28]. Cell cultures were routinely grown using the Smooth Muscle Cell 
Growth Medium 2 containing the following growth additives, all from Promocell Bioscience (Heidelberg, Germany): fetal calf serum (FCS), $5 \%$ (v/v); basic fibroblast growth factor, 2 $\mathrm{ng} / \mathrm{ml}$; epithelial growth factor, $0.5 \mathrm{ng} / \mathrm{ml}$; insulin, $5 \mu \mathrm{g} / \mathrm{ml}$. For experimental purposes, cells between passages 1 and 5 were detached with trypsin, then seeded in 6-well plates (Tissue Culture Products, Trasadingen, Switzerland) and cultured up to high density in the same medium. Then, they were washed with phosphate-buffered saline solution (PBS), and further maintained in culture for $24 \mathrm{~h}$ in $1 \mathrm{ml}$ of FCS-free medium. Cell culture medium, which contains the array of secreted fibroblast factors, including proteases, was then collected and centrifuged at $300 \mathrm{~g}$ for $10 \mathrm{~min}$, then at $18,000 \mathrm{~g}$ for $30 \mathrm{~min}$, in order to eliminate detached cells and debris. In such medium, pro-MMP-2 has been reported to be the major secreted gelatinolytic enzyme [28]. For zymography assay $20 \mu \mathrm{l}$ of cell culture medium were left untreated as control, or incubated with purified or recombinant pseudomonal proteases, or with bacterial secretomes, exactly as described above. For proteolytic activity measurement, $100 \mu \mathrm{l}$ of cell culture medium were left untreated as control, or exposed to $2 \mathrm{nM}$ LasB or to $10 \mathrm{nM}$ native PIV, overnight at $37^{\circ} \mathrm{C}$. After incubation, samples were cooled on ice, and frozen before further analysis (see below).

\section{Immunoblot analysis}

Proteins were denatured in the presence of $2 \%(\mathrm{w} / \mathrm{v})$ sodium dodecyl sulfate (SDS) and $5 \%$ (v/v) 2-mercaptoethanol for $5 \mathrm{~min}$ at $95^{\circ} \mathrm{C}$, followed by electrophoresis on 10 or $14 \%$ polyacrylamide gels (SDS-PAGE) in a Mini-PROTEAN 3 apparatus (Bio-Rad, Hercules, CA, USA). For apparent molecular mass $\left(\mathrm{M}_{r}\right)$ determination, the Page-Ruler Plus prestained Protein Ladder was used as a standard ( $\mathrm{M}_{r}$ range, 10,000-250,000, Fermentas Life Sciences). Separated proteins were then transferred onto polyvinylidene fluoride membranes (PVDF, Pall, Dreieich, Germany) in a semi-dry transfer device (Biometra, Göttingen, Germany). Membranes were incubated for $60 \mathrm{~min}$ in PBS, $\mathrm{pH} 7.4$, containing $0.1 \%$ (w/v) Tween-20 (PBS-T) and $5 \%(\mathrm{w} / \mathrm{v})$ dried skimmed milk, and then overnight at $4{ }^{\circ} \mathrm{C}$ with the primary $\mathrm{Ab}$ diluted in the same medium. After washings in PBS-T, membranes were incubated for 60 min with the HRP-coupled secondary Ab (dilution 1/10,000), then washed. Peroxidase activity was finally developed using the ECL or ECL+ reagent kits (Amersham Biosciences, Little Chalfont, U.K) and the corresponding luminescence was revealed by exposure of membranes to X-ray sensitive blue films (CEA, Newcastle upon Tyne, England). Films were scanned with a GS-800 Calibrated Densitometer (Bio-Rad) and pictures were prepared with the PDQuest 7.1.1 software (Bio-Rad).

\section{Aminoterminal microsequencing}

After electrophoresis under reducing conditions, proteins were transferred onto PVDF membranes, exactly as described above. Protein bands, visualized by Coomassie blue staining $(0.1 \% \mathrm{w} / \mathrm{v})$, were then excised and subjected to automated Edman degradation in a pulse liquid phase sequencer (Procise 492, Applied Biosystems, Foster City, CA).

\section{Gelatin zymography}

For gelatinolytic activity assays, proteins (200 ng of recombinant PIV or uPAR-D1, or $20 \mu 1$ of protease-exposed fibroblast culture medium) were added with $2 \%(\mathrm{w} / \mathrm{v})$ SDS and separated by SDS-PAGE in $10 \%$ polyacrylamide gels, added with $0.2 \%(\mathrm{w} / \mathrm{v})$ gelatin (GibcoInvitrogen, San Diego, CA, USA). Gels were then washed twice for $30 \mathrm{~min}$ in a $2.5 \%(\mathrm{v} / \mathrm{v})$ Triton X-100 solution, developed overnight at $37^{\circ} \mathrm{C}$ in $0.2 \mathrm{M}$ Tris, $5 \mathrm{mM} \mathrm{CaCl}_{2}, \mathrm{pH} 7.8$, and finally stained with Coomassie blue $(0.1 \% \mathrm{w} / \mathrm{v})$. Gels were scanned as described above. 


\section{Proteolytic activity measurement towards synthetic substrates}

For uPA and Pm activity measurement, samples were placed in a 96-well plate and adjusted to a $160 \mu \mathrm{l}$ final volume in $50 \mathrm{mM}$ Tris, $150 \mathrm{mM} \mathrm{NaCl}, \mathrm{pH} 8.0$, in the presence of $0.13 \mathrm{mM}$ benzoyl- $\beta$-Ala-Gly-Arg-paranitroanilide (-pNA) (Pefachrome uPA, Loxo GmbH, Dossenheim, Germany) or in $100 \mathrm{mM}$ Tris, $0.05 \%$ (v/v) Tween-20, $0.01 \%$ (w/v) BSA, pH 7.5 , in the presence of $0.19 \mathrm{mM}$ D-Val-Leu-Lys-pNA (DVLK-902, Molecular Innovations, Southfield, MI, USA), respectively. The release of pNA at $37^{\circ} \mathrm{C}$ was then monitored at 405 $\mathrm{nm}$ in a spectrophotometer (SLT-Labinstruments, Grödig, Austria) over a $30 \mathrm{~min}$ time period. The initial rate of substrate hydrolysis derived from the data was then expressed as $\Delta \mathrm{OD}$, in $\mathrm{mU} / \mathrm{min}$.

For PIV activity measurement, 250 to $500 \mathrm{ng}$ of the recombinant PIV, or $500 \mathrm{ng}$ of control recombinant uPAR-D1, were placed in a 96-well plate and completed to a $250 \mu$ final volume in $50 \mathrm{mM}$ Tris, $100 \mathrm{mM} \mathrm{NaCl}, 0.005 \%$ (v/v) Tween-20, $\mathrm{pH} \mathrm{8}$, in the presence of $0.3 \mathrm{mM}$ of Tosyl-glycyl-prolyl-lysine-4-nitranilideacetate (Roche, Mannheim, Germany), before substrate hydrolysis was recorded as described above.

For MMP-2 activity measurement, samples were placed in a 96-well plate and adjusted to a $200 \mu \mathrm{l}$ final volume in $50 \mathrm{mM}$ Tris, $50 \mathrm{mM} \mathrm{NaCl}, 5 \mathrm{mM} \mathrm{CaCl}_{2}, \mathrm{pH} 7.5$, in the presence of 10 $\mu \mathrm{M}$ (7-methoxy-coumarin-4-yl)acetyl-Pro-Leu-Gly-Leu-(3-[2,4-dinitrophenyl]-L-2,3diaminopropionyl)-Ala-Arg (M-1895, Bachem, Bubendorf, Switzerland). Substrate hydrolysis was then recorded in a spectrofluorimeter (SpectraMax Gemini EM, Molecular Devices, Sunnyvale, CA, USA) over a $30 \mathrm{~min}$ time period, with excitation and emission wavelengths of 355 and $460 \mathrm{~nm}$, respectively.

\section{Determination of the kinetic parameters of pro-uPA activation}

LasB $(0.01 \mathrm{nM})$, native PIV $(0.1 \mathrm{nM})$ or Pm $(0.01 \mathrm{nM}$, standardized by active-site titration using 4-methylumbelliferyl $p$-guanidinobenzoate [29]), were incubated with varying concentrations of pro-uPA $(0-10 \mu \mathrm{M})$ in $50 \mathrm{mM}$ HEPES, $150 \mathrm{mM} \mathrm{NaCl}, 0.01 \%$ azide, $0.01 \%$ Triton X-100, pH 7.4. Zymogen activation was followed by recording the release of 7amino-4-methylcoumarin (AMC) generated by cleavage of the reporter substrate Boc-LeuGly-Arg-7-amino-4-methylcoumarin $(20 \mu \mathrm{M})$ by activated uPA. In each experiment, the specific activity of uPA towards the reporter substrate was determined using active-sitetitrated uPA $(0-10 \mathrm{nM})$ under the same conditions. Substrate cleavage by pro-uPA, LasB, PIV or Pm was negligible. Data were recorded every $30 \mathrm{sec}$ for 30 min using a HTS 7000 Bio Assay Reader (PerkinElmer, Rodgau-Jügesheim, Germany), with excitation and emission wavelength of 360 and $465 \mathrm{~nm}$, respectively.

The time-dependent increase of AMC was fitted to a modification of an integrated rate equation describing a coupled zymogen activation and reporter reaction initially used to analyze the activation of plasminogen $[30,31]: \mathrm{AMC}_{(\mathrm{t})}=0.5 \cdot \mathrm{a}_{\mathrm{rs}} \cdot \mathrm{V}_{\mathrm{z}} \cdot\left(\mathrm{t}-\mathrm{t}_{0}\right)^{2}+\mathrm{AMC}_{0}$, where $\mathrm{AMC}_{(\mathrm{t})}$ and $\mathrm{AMC}_{0}$ are the concentrations of $\mathrm{AMC}$ measured at time $\mathrm{t}$ and baseline, respectively, $t_{0}$ the delay between the start of the reaction and the first measurement, $V_{z}$ the velocity of zymogen activation, and $\mathrm{a}_{\mathrm{rs}}$ the specific activity of uPA towards the reporter substrate. The zymogen activation velocities $\mathrm{V}_{\mathrm{z}}$ at different pro-uPA concentrations calculated from at least 3 different experiments were subsequently fitted to the MichaelisMenten equation to obtain the kinetic parameters $\mathrm{K}_{\mathrm{m}}, \mathrm{k}_{\mathrm{cat}}$ and $\mathrm{k}_{\mathrm{cat}} / \mathrm{K}_{\mathrm{m}}$. Both curve fitting steps were performed with proFit (Quantum Soft, Uetikon am See, Switzerland) using a LevenbergMarquardt algorithm.

\section{Data presentation}

Results are expressed as mean plus standard error of the mean (+SEM) for the indicated number of experiments performed independently. 


\section{RESULTS}

\section{Activation of human pro-uPA by purified LasB}

To investigate the capacity of pseudomonal LasB to activate pro-uPA, recombinant human pro-uPA (200 ng) was first exposed to increasing concentrations (i.e., 1 to $100 \mathrm{nM}$ ) of the purified bacterial protease for $60 \mathrm{~min}$ at $37^{\circ} \mathrm{C}$. It is of note that such LasB concentrations are comparable to those produced by bacteria in vitro (i.e., up to $500 \mathrm{nM}$ [32]) and actually detected in vivo, such as in the airways of patients with cystic fibrosis (i.e., up to $300 \mathrm{nM}$ [33]). Immunoblot analysis performed under reducing conditions revealed that LasB progressively converts single-chain pro-uPA $\left(\mathrm{M}_{r} \approx 47,000\right)$ into two molecular species with $\mathrm{M}_{r} \approx 29,000$ and $\approx 17,000$ (Fig. 1A). These molecular masses are similar to those of the Band A-chains of UPA, i.e., the catalytic and binding domains of the protease, respectively, as they are generated via exposure of pro-uPA to its canonical activator Pm (Fig. 1A). Accordingly, aminoterminal microsequencing indicated that these LasB-generated species possess aminoterminal sequences Ile-Ile-Gly-Gly and Ser-Asn-Glu-Leu, respectively, corresponding to amino acids 159-163 and 1-4 of human pro-uPA. Both fragments are thus generated upon hydrolysis of the Lys ${ }^{158}$-Ile ${ }^{159}$ peptide bond within pro-uPA (Table 1), i.e., the activation cleavage site. Proteolytic activity measurement using a selective uPA chromogenic substrate confirmed that pro-uPA can be readily activated by LasB, with a bacterial protease concentration as low as $1 \mathrm{nM}$ and an enzyme/substrate molar ratio of 1/450 (Fig. 1B). On one hand, after exposure of pro-uPA (200 ng) to LasB in the range 10-100 nM, the activity of LasB-generated uPA reaches up to $75 \%$ of the activity displayed by $200 \mathrm{ng}$ of purified human active uPA, used as a positive control (Fig. 1B). On the other hand, LasB-driven prouPA activation is actually comparable to the activation of pro-uPA resulting from exposure to $\mathrm{Pm}$ in an enzyme/substrate molar ratio of $1 / 10$ (Fig. 1B). It is of note that for a high LasB concentration (i.e., $100 \mathrm{nM}$, Fig. 1A), the A-chain is further converted into a $\mathbf{M}_{r} \approx 13,000$ molecular species, bearing a Phe-Ser-Asn-Ile aminoterminus and thus resulting from the hydrolysis of the $\mathrm{Tyr}^{24}-\mathrm{Phe}^{25}$ peptide bond within the growth factor domain that makes part of the uPA A-chain (Table 1). In contrast, the B-chain remains remarkably stable. Complementary experiments showed an efficient, time-dependent activation of pro-uPA by LasB, detectable as soon as 15 min following exposure to $10 \mathrm{nM} \mathrm{LasB}$, while a further processing of the A-chain is again observed for the longest incubation time (i.e., $5 \mathrm{~h}$; data not illustrated). Finally, to characterize the efficiency of pro-uPA activation by LasB, we determined the kinetic parameters of the reaction, and found $\mathrm{k}_{\mathrm{cat}}, \mathrm{K}_{\mathrm{m}}$ and $\mathrm{k}_{\mathrm{cat}} / \mathrm{K}_{\mathrm{m}}$ values of 4.9 $\pm 0.34 \mathrm{~s}^{-1}, 8.9 \pm 1.1 \mu \mathrm{M}$ and $0.55 \pm 0.08 \mu \mathrm{M}^{-1} \mathrm{~s}^{-1}$, respectively, to be compared to values obtained with active site-titrated Pm, with $\mathrm{k}_{\text {cat }} 4.2 \pm 0.13 \mathrm{~s}^{-1}, \mathrm{~K}_{\mathrm{m}} 3.2 \pm 0.24 \mu \mathrm{M}$ and $\mathrm{k}_{\text {cat }} / \mathrm{K}_{\mathrm{m}} 1.3$ $\pm 0.11 \mu \mathrm{M}^{-1} \mathrm{~s}^{-1}$.

\section{Activation of human pro-uPA by bacterial secretomes}

We next explored whether the secretome from a pseudomonal LasB-expressing strain (i.e., PAO1), could trigger activation of pro-uPA. Within such a secretome, LasB is both the major secreted bacterial protein and one major protease, reaching a concentration up to $500 \mathrm{nM}$ (see the gelatinolytic activity of the PAO1-Sec in Fig. 3E and 5D, right-hand panels, and [32]). Exposure of recombinant human pro-uPA to this secretome actually results in its activation, as judged by both immunoblot analysis (Fig. 1C) and proteolytic activity measurement (Fig. 1D). This processing is already detectable with a $1 / 2,500$ dilution (i.e., $0.04 \%, \mathrm{v} / \mathrm{v}$ ) of the PAO1-Sec, while a 1/100 dilution (i.e., $1 \%$, v/v) results, as observed with purified LasB, in a further processing of the A-chain (Fig. 1C). In order to evaluate the role of LasB as a major pro-uPA activating enzyme within the pseudomonal secretome, we analyzed the capacity of the secretome from an isogenic LasB-deficient strain (i.e., PDO240) to activate the human 
zymogen. Using the PDO240-Sec, a significant pro-uPA activation is observed (Fig. 1E and 1F), although limited as compared to that produced with the PAO1-Sec.

Altogether these results suggest that LasB is indeed a major pseudomonal pro-uPA activator, although $P$. aeruginosa also secretes one or several other pro-uPA activator(s).

\section{Identification of PIV as a potent pro-uPA activator}

In order to identify the unknown pro-uPA activator(s) expressed within the pseudomonal secretome, pro-uPA was exposed to the PDO240-Sec in the presence of selective protease inhibitors, before analyzing pro-uPA activation by immunoblot. Pro-uPA activation by the LasB-deficient PDO240-Sec is not affected by metallo-, cysteine- or aspartic-protease inhibitors (i.e., OPA, E-64 and pepstatin A, respectively), while it is clearly reduced, although not abrogated, in the presence of the wide spectrum Ser-protease inhibitor benzamidine (Fig. 2A). Consistently, and while the cation chelator OPA totally inhibits pro-uPA activation by $100 \mathrm{nM}$ purified LasB (Fig. 2B, right-hand panel), it is not sufficient to fully repress activation of the zymogen by the PAO1-Sec, although activation is drastically impaired (Fig. 2B, left-hand panel). This reflects both a major LasB-dependent and a minor LasB- and metalloprotease-independent pro-uPA activation by the PAO1-Sec. As observed with the PDO240-Sec, the metalloprotease-independent pathway of activation is actually sensitive to a Ser-protease inhibitor, as indicated by the almost total abrogation of activation provided by the combination of OPA and benzamidine, whereas none of the other inhibitor combinations (OPA/E-64, OPA/pepstatin A) adds any further inhibition over that provided by OPA alone (Fig. 2B, left-hand panel). Taken together, these observations confirm that, besides LasB, activation of human pro-uPA by the pseudomonal secretome also involves a Ser-protease activity.

Among the pseudomonal secreted Ser-proteases is PIV, also referred to as PrpL or Ps-1 [3436]. This enzyme, which activity was reported to be affected, but not completely blocked, by benzamidine [36], targets substrates bearing a Lys residue at the P1 position of the sessile peptide bond $[23,36]$. Such inhibitor and substrate specificities thus share similarities with the metalloprotease-independent pro-uPA activation that is observed upon its exposure to pseudomonal secretomes. In support to the assumption that PIV may be a pro-uPA activator, it must be noted that PIV is expressed to significant and similar levels in both the PAO1 and PDO240 secretomes, as demonstrated by evaluation of the global gelatinolytic activity of the secretomes using zymography (Fig. 3E). Indeed, the gelatinolytic profile of the PAO1-Sec identifies, under the particular electrophoretic conditions used, three major components with $\mathrm{M}_{r}$ values of $\approx 52,000, \approx 167,000$ and $\geq 250,000$, which, based on previous reports [15, 35], correspond to the alkaline protease/AprA, LasB, and PIV, respectively. The gelatinolytic profile of the PDO240-Sec shows the alkaline protease/AprA and PIV components, with activities similar to those observed in the PAO1-Sec, while lacking, as expected, the LasB component. In order to ascertain that PIV can be a pro-uPA activator, the DNA encoding for mature PIV was cloned from the PAO1 genome [37] and then inserted into a prokaryotic expression plasmid encoding for a translation product bearing an aminoterminal (His) 6 -tag, as schematically depicted in Fig. 3A, following a procedure previously described for a number of eukaryotic Ser-proteases [38, 39]. As expected, plasmid transformation in E. coli, followed by protein expression, extraction under denaturating conditions and purification, yields a major $\mathrm{M}_{r} \approx 30,000$ fusion protein (Fig. 3B). It is of note that the two-step purification procedure (i.e., $\mathrm{pH}$-dependent affinity chromatography on Ni-NTA followed by a second NiNTA chromatography using an imidazol concentration gradient) results in a rather pure preparation of recombinant PIV, which however remains slightly contaminated by a $\mathrm{M}_{r} \approx$ 27,000 protein (Fig. 3B). This latter contaminant is also present in the final preparation of an E. coli-expressed, (His) ${ }_{6}$-tagged protein generated through an identical procedure and taken as 
a negative control, in this case the $\mathrm{M}_{r} \approx 14,500 \mathrm{D} 1$ domain of the uPA receptor, uPAR (uPAR-D1, Fig. 3B). SDS-PAGE performed under reducing conditions indicates that, upon dialysis-based protein refolding, recombinant PIV readily proceeds itself into smaller species with $\mathrm{M}_{r} \approx 20,000$ and $\approx 17,000$ (Fig. 3B), a feature which is also observed when proteins are analyzed under nonreducing conditions (data not illustrated). These truncated PIV species remain reactive with an $\mathrm{Ab}$ directed against the His-tag (Fig. 3C), demonstrating that they result from cleavage of the enzyme within its carboxyterminal region. Remarkably, such PIV autoprocessing has already been reported for naturally produced, as well as for recombinantly expressed PIV, and was found not to affect the enzyme proteolytic activity [23, 35, 37, 40, 41]. Accordingly, our recombinant PIV preparation is active towards a known PIV chromogenic susbstrate, chromozyme PL [34] (Fig. 3D) and appears, upon gelatin zymography, as a high $\mathrm{M}_{r}$ doublet species (Fig. 3E). In contrast, the preparation of recombinant uPAR-D1 is devoid of any peptidase/proteinase activity in both assays (Fig. 3D and 3E).

Exposure of recombinant human pro-uPA to increasing concentrations of recombinant PIV (7.5-200 $\mathrm{nM})$ results in a progressive conversion of single-chain pro-uPA into two-chain, active UPA, with uPA activity reaching up to $80 \%$ of the activity of an equivalent amount of purified uPA, whereas, in contrast, recombinant uPAR-D1 leaves pro-uPA unchanged and inactive (Fig. 4A and 4B). These data were validated by the observation that native PIV (100 $\mathrm{nM}$ ), directly purified from the extracellular medium of pseudomonal cultures, also targets and activates the zymogen (Fig. 4A and 4B). It is of note that, for a high PIV concentration (i.e., over $100 \mathrm{nM}$ PIV), a further processing of the uPA A-chain is observed, leading to the generation of a $\mathrm{M}_{r} \approx 13,000$ species which results from hydrolysis of the $\mathrm{Lys}^{23}-\mathrm{Tyr}^{24}$ peptide bond (Fig. 4A and Table 1). In addition, exposure of pro-uPA to recombinant PIV in the presence of selective protease inhibitors revealed that, as observed with bacterial secretomes, PIV-induced pro-uPA activation is drastically sensitive to benzamidine, whereas it is not affected by the other tested inhibitors (data not illustrated). Finally, kinetic parameters of pro$\mathrm{uPA}$ activation by native PIV were found to be $\mathrm{k}_{\text {cat }}=0.73 \pm 0.04 \mathrm{~s}^{-1}, \mathrm{~K}_{\mathrm{m}}=6.2 \pm 0.65 \mu \mathrm{M}$ and $\mathrm{k}_{\mathrm{cat}} / \mathrm{K}_{\mathrm{m}} 0.12 \pm 0.01 \mu \mathrm{M}^{-1} \mathrm{~s}^{-1}$.

Altogether, our results thus demonstrate that within the pseudomonal secretome, not only LasB, but also PIV targets and activates pro-uPA.

\section{Identification of other substrates for pseudomonal proteases within the host Plg activation system}

We further analyzed whether PIV cleaves other known LasB targets within the human Plg activation system (i.e., UPAR, PAI-1 and pro-MMP-2), and, more generally, whether pseudomonal proteases can directly process Plg [32, 42-44].

Exposure of Plg to either purified LasB $(10 \mathrm{nM})$ or to $1 \%$ of the LasB-expressing PAO1-Sec results in the generation of identical new molecular species, including a doublet with $\mathrm{M}_{r} \approx$ $72,000 / 65,000$, and a singlet with $\mathrm{M}_{r} \approx 40,000$ (Fig. 5A). These species are distinct from the $88 / 84 \mathrm{kDa} A$-chain, and from the $28 \mathrm{kDa}$ B-chain produced upon Plg activation by uPA (data not illustrated). In line with this, LasB-processed Plg does not show any proteolytic activity towards a synthetic Pm chromogenic substrate (data not illustrated). Aminoterminal microsequencing allowed to establish that these Plg-derived species result from hydrolysis of the $\mathrm{Ser}^{441}-\mathrm{Val}^{442}$ and $\mathrm{Val}^{442}-\mathrm{Val}^{443}$ peptide bonds within human Plg (Table 1). They thus correspond to two glycosylation variants of angiostatin, encompassing the $\mathrm{Plg}$ kringle domains 1 to $4\left(\mathrm{M}_{r} \approx 72,000 / 65,000\right)$, and to mini-Plg, composed of the inactive catalytic domain and of the kringle domain $5\left(\mathrm{M}_{r} \approx 40,000\right)$. For higher LasB concentrations (i.e., 100 $\mathrm{nM}$ ) or with $20 \% \mathrm{PAO} 1-\mathrm{Sec}$, these Plg fragments are further processed into $\mathrm{M}_{r} \approx$ $43,000 / 39,000$ and 29,000 forms, which were found to result from further carboxyterminal 
processing of both angiostatin and mini-Plg. By contrast, neither the LasB-deficient PDO240Sec, nor recombinant PIV has any detectable effect on the structure and activity of human Plg (Fig. 5A and data not shown, respectively).

As we recently reported [32], it was confirmed that purified LasB (100 nM), as well as the PAO1-derived secretome (20\%), convert recombinant soluble uPAR $\left(\mathrm{M}_{r} \approx 55,000\right)$ into a $\mathrm{M}_{r}$ $\approx 45,000$ D2D3 truncated species lacking the shed aminoterminal D1 domain (Fig. 5B), which reflects hydrolysis within the UPAR D1-D2 linker region. Exposure of UPAR either to the PDO240-Sec or to recombinant PIV shows no evidence for a proteolytic processing of this important cell receptor (Fig. 5B).

Furthermore, LasB was reported to target and inactivate PAI-1 [42]. Accordingly, LasB at $100 \mathrm{nM}$, as well as the PAO1-Sec $(20 \%)$, process recombinant PAI-1 $\left(\mathrm{M}_{r} \approx 57,000\right)$ into a slightly shorter molecular species with $\mathrm{M}_{r} \approx 54,000$ (Fig. 5Cl). This feature has also been reported for other bacterial thermolysin-related proteases [45], in which case it corresponds to cleavage within the carboxyterminal domain of the serpin, in the vicinity of the reactive center loop. By contrast, PAI-1 was not processed at all using the LasB-deficient secretome or recombinant PIV (Fig. 5C).

Finally, this study confirms that LasB at $100 \mathrm{nM}$, as well as the PAO1-Sec in the range 1-20 $\%$, transform pro-MMP-2, as it is spontaneously released by human vascular fibroblasts in their culture medium with a $\mathrm{M}_{r} \approx 63,000$ [28], into the $\mathrm{M}_{r} \approx 57,000$ active form of the enzyme, as judged by gelatin zymography (Fig. 5D) [43, 44]. Activation of fibroblast-derived pro-MMP-2 by purified LasB was also confirmed by protease activity measurement towards a MMP-selective fluorigenic substrate (data not shown). By contrast, under conditions which trigger efficient pro-uPA activation, recombinant PIV or PIV naturally expressed by the PDO240 strain, leave pro-MMP-2 unaffected (Fig. 5D).

Similar results regarding the absence of Plg, uPAR, PAI-1 or pro-MMP-2 processing by PIV, were also obtained using the purified native protease (data not shown). 


\section{DISCUSSION}

A number of pathogenic bacteria take profit on the host Plg system to promote their own spread and invasion through host tissues and physiological barriers, in a way that mimics that observed for malignant tumor cells [7-9]. In the case of $P$. aeruginosa, $\mathrm{Plg} / \mathrm{Pm}$ binding at the bacterial surface has been reported for a number of reference and clinical isolates [22, 46, 47]. Moreover, bound Pm promotes invasion of $P$. aeruginosa within fibrin and reconstituted basement membrane matrices [22]. However, in contrast to $S$. aureus and $Y$. pestis [7, 9, 13], $P$. aeruginosa had not been reported so far to display any activator for either pro-uPA, tPA or Plg.

In the present study, we establish that $P$. aeruginosa secretes proteases that directly activate the zymogen form of human uPA, including the thermolysin-like metallopeptidase LasB and the Ser-protease PIV. With a $\mathrm{k}_{\text {cat }} / \mathrm{K}_{\mathrm{m}}$ of $0.55 \mu \mathrm{M}^{-1} \mathrm{~s}^{-1}$, LasB appears as a potent prouPA activator, with a specificity constant in the range of that observed for $\mathrm{Pm}\left(\mathrm{k}_{\mathrm{cat}} / \mathrm{K}_{\mathrm{m}}\right.$ of Pm $\left.=1.3 \mu \mathrm{M}^{-1} \mathrm{~s}^{-1}\right)$, whereas PIV is about five times less efficient than LasB $\left(\mathrm{k}_{\mathrm{cat}} / \mathrm{K}_{\mathrm{m}}=0.12 \mu \mathrm{M}^{-1}\right.$ $\mathrm{s}^{-1}$ ). Still both proteases activate pro-uPA much more efficiently than the S. aureus-expressed, thermolysin-like protease aureolysin $\left(\mathrm{k}_{\mathrm{cat}} / \mathrm{K}_{\mathrm{m}}\right.$ of aureolysin $\left.0.003 \mu \mathrm{M}^{-1} \mathrm{~s}^{-1}\right)$ [13]. Remarkably, besides $P$. aeruginosa, several pathogenic bacteria that express thermolysin-like peptidases, including S. aureus[13], Burkholderia cepacia and Serratia marcescens (Beaufort et al., unpublished results), also display pro-uPA activating capacities. It is thus tempting to propose that pro-uPA activation might be a feature common to bacterial M4-related peptidases and, thus, a property shared by other pathogenic bacterial species.

Within human tissues, (pro-)uPA is locally expressed at low levels by epithelial, endothelial and stromal cells $[11,12]$. Upon inflammation or infection, its expression by these cells is increased, while it is also massively released from neutrophils recruited at the site of inflammation/infection, where plasma proteins, including Plg, also exudate [11, 12]. As prouPA is positioned upstream in the auto-amplified uPA/Pm/MMPs proteolytic loop, its activation by bacterial enzymes certainly results in an efficient triggering and maintenance of this host proteolytic system. Concerning Plg, the zymogen was not processed into active Pm by any of the pseudomonal proteases. Plg was, however, cleaved by LasB, but not by PIV, into (i) mini-Plg, that can be further converted into mini-Pm [13], and (ii) angiostatin, that displays the interesting capacity to dampen leukocytes migration, and might thus provide bacteria with immunoevasive capacities [48]. Inactivation of host serpins and/or activation of pro-MMPs, are other known features of bacterial proteases that may allow a pathogen to use one of the major extracellular proteolytic system of the host for its own dissemination $[7,13$, 43, 44]. With this respect, we confirmed that LasB neutralizes PAI-1 [42], whereas it activates pro-MMP-2 [43, 44], thus further participating to the bacterial-driven deregulation of the otherwise tightly regulated Plg activation system. By contrast, PIV leaves both substrates unaffected. Of note is the fact that the proteolytic processing of the other principal Plg activator, tPA, by pseudomonal proteases was not investigated here, since its activation is promoted by its binding to fibrin rather than by proteolysis [11].

Although the effects of bacteria and bacterial compounds on the host Plg activation system have been extensively analyzed [7], the reciprocal activity of the Plg system on bacteria has been poorly investigated so far, with exception of (pro-)uPA, which promotes pseudomonal growth and enhances the bacterial proteolytic activity $[49,50]$. Interestingly, we found that both LasB and PIV process the A-chain of (pro-)uPA, a feature which prevents uPA binding to its cellular receptor uPAR [51]. Along with this, LasB targets the D1-D2 linker region within uPAR, which abrogates uPA/uPAR interaction [32]. Altogether, we speculate that the Pseudomonas-dependent disruption of the (pro-)uPA/uPAR complex might increase the bioavailability of the otherwise membrane-anchored (pro-)uPA, thereby promoting bacterial growth. 
In contrast to the rather well-characterized LasB, only little information is currently available concerning PIV. PIV is widely expressed among reference and clinical isolates [37, 52], and is a potent virulence factor in eye and lung infection models [35, 37, 41]. Interestingly, this Ser-peptidase appears to be clearly distinct from eukaryotic Ser-proteases. On one hand, PIV readily processes its own mature catalytic domain $(\approx 30 \mathrm{kDa})$ into smaller 20 and $17 \mathrm{kDa}$ fragments, a cleavage that does not impair its proteolytic activity [40, 41]. On the other hand, it displays a bulky, 186 amino acids pro-domain, which has been proposed to prevent intracellular auto-processing, or to act as a chaperone protein [41]. We now establish that replacement of the PIV pro-domain by a short, 17 residues sequence, actually leads to an active form of the enzyme, although it is still N-terminally extended. This suggests that PIV activation does not result from an insertion of the $\mathrm{N}$-terminus of the mature catalytic domain into a cleft near the active site, triggering a conformational rearrangement of the latter as observed with eukaryotic Ser-proteases [53], but rather from uncovering of the already preexisting active site, as described e.g. for subtilisin-like peptidases [54]. Concerning the PIV substrate specificity, this protease targets peptide bonds bearing a basic residue in the P1 position [23], whereas LasB targets peptide bonds bearing a bulky or apolar residue in the P1' position [4]. As a consequence, and although these two proteases belong to different protease families, they both hydrolyse the unique activation cleavage site within human pro-uPA, i.e., Lys $^{158}$-Ile ${ }^{159}$. In contrast, a number of LasB substrates (e.g., Plg, uPAR, PAI-1, pro-MMP-2; Table 1) are not affected at all by PIV, or are processed at different peptide bonds (e.g., the uPA A-chain; Table 1).

In conclusion, the ubiquitous bacterium $P$. aeruginosa expresses proteases, including the well-known thermolysin-like metallopeptidase LasB, and the more recently described PIV, which both combine to hijack the host Plg system, primarily via pro-uPA activation, and, in the case of LasB, via PAI-1 inactivation and pro-MMP-2 activation. Such processes might constitute an important virulence mechanism, which may well utilize other pathogenic bacteria expressing similar extracellular proteases. 


\section{ACKNOWLEDGEMENTS}

The authors express gratitude to Sabine Streicher and Antoine Freyss for excellent technical assistance, to Reinhard Mentele for help with amminoterminal microsequencing, to Michel Chignard for providing purified LasB, to Christine Choqueux for providing the procedure for culturing human myofibroblasts, and to Wolfram Bode for helpful discussions.

\section{FUNDING}

This work was supported by fellowships from the Alexander von Humboldt Stiftung, Bonn, Germany, and from the Fondation Lefoulon-Delalande/Institut de France, Paris, France (to N.B.), by an Erasmus student mobility grant (to P.S.), and by a collaboration grant from the Centre de Coopération Universitaire Franco-Bavarois/Bayerisch-Französisches Hochschulzentrum (CCUFB/BFHZ), Munich, Germany (to N.B. and V.M.). D.P. is Chargé de Recherche at the Institut National des Sciences du Vivant within the Centre National de la Recherche Scientifique, Paris, France. 


\section{REFERENCES}

1 Barrett, A. J. (2004) Bioinformatics of proteases in the MEROPS database. Curr. Opin. Drug. Discov. Devel. 7, 334-341

2 Kukkonen, M. and Korhonen, T. K. (2004) The omptin family of enterobacterial surface proteases/adhesins: from housekeeping in Escherichia coli to systemic spread of Yersinia pestis. Int. J. Med. Microbiol. 294, 7-14

3 Travis, J., Potempa, J. and Maeda, H. (1995) Are bacterial proteinases pathogenic factors? Trends Microbiol. 3, 405-407

4 Supuran, C. T., Scozzafava, A. and Clare, B. W. (2002) Bacterial protease inhibitors. Med. Res. Rev. 22, 329-372

5 Coombes, B. K., Valdez, Y. and Finlay, B. B. (2004) Evasive maneuvers by secreted bacterial proteins to avoid innate immune responses. Curr. Biol. 14, R856-867

6 Potempa, J. and Pike, R. N. (2009) Corruption of innate immunity by bacterial proteases. J. Innate Immun. 1, 70-87

7 Lahteenmaki, K., Edelman, S. and Korhonen, T. K. (2005) Bacterial metastasis: the host plasminogen system in bacterial invasion. Trends Microbiol. 13, 79-85

8 Bergmann, S. and Hammerschmidt, S. (2007) Fibrinolysis and host response in bacterial infections. Thromb. Haemost. 98, 512-520

9 Degen, J. L., Bugge, T. H. and Goguen, J. D. (2007) Fibrin and fibrinolysis in infection and host defense. J. Thromb. Haemost. 5, 24-31

10 Castellino, F. J. and Ploplis, V. A. (2005) Structure and function of the plasminogen/plasmin system. Thromb. Haemost. 93, 647-654

11 Lijnen, H. R. (2001) Elements of the fibrinolytic system. Ann. N. Y. Acad. Sci. 936, 226-236

12 Ellis, V. (2003) Plasminogen activation at the cell surface. Curr. Top. Dev. Biol. 54, 263-312

13 Beaufort, N., Wojciechowski, P., Sommerhoff, C. P., Szmyd, G., Dubin, G., Eick, S., Kellermann, J., Schmitt, M., Potempa, J. and Magdolen, V. (2008) The human fibrinolytic system is a target for the staphylococcal metalloprotease aureolysin. Biochem. J. 410, 157165

14 Pier, G. B. and Ramphal, R. (2005) Pseudomonas aeruginosa. In: Mandell, Douglas Bennet's principles and practice of infectious diseases, $6^{\text {th }}$ edition, 2587-2615

15 Caballero, A. R., Moreau, J. M., Engel, L. S., Marquart, M. E., Hill, J. M. and O'Callaghan, R. J. (2001) Pseudomonas aeruginosa protease IV enzyme assays and comparison to other Pseudomonas proteases. Anal. Biochem. 290, 330-337

16 Matsumoto, K. (2004) Role of bacterial proteases in pseudomonal and serratial keratitis. Biol. Chem. 385, 1007-1016

17 Kida, Y., Higashimoto, Y., Inoue, H., Shimizu, T. and Kuwano, K. (2008) A novel secreted protease from Pseudomonas aeruginosa activates NF-kappaB through proteaseactivated receptors. Cell. Microbiol. 10, 1491-1504

18 Marquart, M. E., Caballero, A. R., Chomnawang, M., Thibodeaux, B. A., Twining, S. S. and O'Callaghan, R. J. (2005) Identification of a novel secreted protease from Pseudomonas aeruginosa that causes corneal erosions. Invest. Ophthalmol. Vis. Sci. 46, 3761-3768

19 Tang, A., Marquart, M. E., Fratkin, J. D., McCormick, C. C., Caballero, A. R., Gatlin, H. P. and O'Callaghan, R. J. (2009) Properties of PASP: a Pseudomonas protease capable of mediating corneal erosions. Invest. Ophthalmol. Vis. Sci. 50, 3794-3801

20 Thayer, M. M., Flaherty, K. M. and McKay, D. B. (1991) Three-dimensional structure of the elastase of Pseudomonas aeruginosa at 1.5-A resolution. J. Biol. Chem. 266, 28642871 
21 Banbula, A., Potempa, J., Travis, J., Fernandez-Catalan, C., Mann, K., Huber, R., Bode, W. and Medrano, F. (1998) Amino-acid sequence and three-dimensional structure of the Staphylococcus aureus metalloproteinase at 1.72 A resolution. Structure. 6, 1185-1193

22 da Silva, C. M., de Abreu Vidipo, L., Nishi, R. and Cristina Plotkowski, M. (2004) Binding of plasminogen to Pseudomonas aeruginosa results in formation of surfaceassociated plasmin and enhanced bacterial invasiveness. Microb. Pathog. 36, 59-66

23 Engel, L. S., Hill, J. M., Caballero, A. R., Green, L. C. and O'Callaghan, R. J. (1998) Protease IV, a unique extracellular protease and virulence factor from Pseudomonas aeruginosa. J. Biol. Chem. 273, 16792-16797

24 Grebenchtchikov, N., Sweep, C. G., Geurts-Moespot, A., Piffanelli, A., Foekens, J. A. and Benraad, T. J. (2002) An ELISA avoiding interference by heterophilic antibodies in the measurement of components of the plasminogen activation system in blood. J. Immunol. Methods. 268, 219-231

25 Luther, T., Magdolen, V., Albrecht, S., Kasper, M., Riemer, C., Kessler, H., Graeff, H., Muller, M. and Schmitt, M. (1997) Epitope-mapped monoclonal antibodies as tools for functional and morphological analyses of the human urokinase receptor in tumor tissue. Amer. J. Pathol. 150, 1231-1244

26 Stover, C. K., Pham, X. Q., Erwin, A. L., Mizoguchi, S. D., Warrener, P., Hickey, M. J., Brinkman, F. S., Hufnagle, W. O., Kowalik, D. J., Lagrou, M., Garber, R. L., Goltry, L., Tolentino, E., Westbrock-Wadman, S., Yuan, Y., Brody, L. L., Coulter, S. N., Folger, K. R., Kas, A., Larbig, K., Lim, R., Smith, K., Spencer, D., Wong, G. K., Wu, Z., Paulsen, I. T., Reizer, J., Saier, M. H., Hancock, R. E., Lory, S. and Olson, M. V. (2000) Complete genome sequence of Pseudomonas aeruginosa PA01, an opportunistic pathogen. Nature. 406, 959-964 27 McIver, K. S., Kessler, E., Olson, J. C. and Ohman, D. E. (1995) The elastase propeptide functions as an intramolecular chaperone required for elastase activity and secretion in Pseudomonas aeruginosa. Mol. Microbiol. 18, 877-889

28 Fondard, O., Detaint, D., Iung, B., Choqueux, C., Adle-Biassette, H., Jarraya, M., Hvass, U., Couetil, J. P., Henin, D., Michel, J. B., Vahanian, A. and Jacob, M. P. (2005) Extracellular matrix remodelling in human aortic valve disease: the role of matrix metalloproteinases and their tissue inhibitors. Eur. Heart. J. 26, 1333-1341

29 Jameson, G. W., Roberts, D. V., Adams, R. W., Kyle, W. S. and Elmore, D. T. (1973) Determination of the operational molarity of solutions of bovine alpha-chymotrypsin, trypsin, thrombin and factor Xa by spectrofluorimetric titration. Biochem. J. 131, 107-117

30 Liu, J. N. and Gurewich, V. (1993) The kinetics of plasminogen activation by thrombin-cleaved pro-urokinase and promotion of its activity by fibrin fragment E-2 and by tissue plasminogen activator. Blood. 81, 980-987

31 Castro, M. J., Kingston, I. B. and Anderson, S. (1995) A spectrophotometric assay for the determination of the catalytic efficiency of plasminogen activators using a slowly hydrolyzed plasmin substrate. Anal. Biochem. 226, 225-231

32 Leduc, D., Beaufort, N., de Bentzmann, S., Rousselle, J. C., Namane, A., Chignard, M. and Pidard, D. (2007) The Pseudomonas aeruginosa LasB metalloproteinase regulates the human urokinase-type plasminogen activator receptor through domain-specific endoproteolysis. Infect. Immun. 75, 3848-3858

33 Jaffar-Bandjee, M. C., Lazdunski, A., Bally, M., Carrere, J., Chazalette, J. P. and Galabert, C. (1995) Production of elastase, exotoxin A, and alkaline protease in sputa during pulmonary exacerbation of cystic fibrosis in patients chronically infected by Pseudomonas aeruginosa. J. Clin. Microbiol. 33, 924-929

34 O'Callaghan, R. J., Engel, L. S., Hobden, J. A., Callegan, M. C., Green, L. C. and Hill, J. M. (1996) Pseudomonas keratitis. The role of an uncharacterized exoprotein, protease IV, in corneal virulence. Invest. Ophthalmol. Vis. Sci. 37, 534-543 
35 Wilderman, P. J., Vasil, A. I., Johnson, Z., Wilson, M. J., Cunliffe, H. E., Lamont, I. L. and Vasil, M. L. (2001) Characterization of an endoprotease (PrpL) encoded by a PvdSregulated gene in Pseudomonas aeruginosa. Infect. Immun. 69, 5385-5394

36 Elliott, B. W., Jr. and Cohen, C. (1986) Isolation and characterization of a lysinespecific protease from Pseudomonas aeruginosa. J. Biol. Chem. 261, 11259-11265

37 Caballero, A., Thibodeaux, B., Marquart, M., Traidej, M. and O'Callaghan, R. (2004) Pseudomonas keratitis: protease IV gene conservation, distribution, and production relative to virulence and other Pseudomonas proteases. Invest. Ophthalmol. Vis. Sci. 45, 522-530

38 Debela, M., Magdolen, V., Grimminger, V., Sommerhoff, C., Messerschmidt, A., Huber, R., Friedrich, R., Bode, W. and Goettig, P. (2006) Crystal structures of human tissue kallikrein 4: activity modulation by a specific zinc binding site. J. Mol. Biol. 362, 1094-1107

39 Debela, M., Goettig, P., Magdolen, V., Huber, R., Schechter, N. M. and Bode, W. (2007) Structural basis of the zinc inhibition of human tissue kallikrein 5. J. Mol. Biol. 373, 1017-1031

40 Traidej, M., Marquart, M. E., Caballero, A. R., Thibodeaux, B. A. and O'Callaghan, R. J. (2003) Identification of the active site residues of Pseudomonas aeruginosa protease IV. Importance of enzyme activity in autoprocessing and activation. J. Biol. Chem. 278, 25492553

41 Traidej, M., Caballero, A. R., Marquart, M. E., Thibodeaux, B. A. and O'Callaghan, R. J. (2003) Molecular analysis of Pseudomonas aeruginosa protease IV expressed in Pseudomonas putida. Invest. Ophthalmol. Vis. Sci. 44, 190-196

42 Boudier, C., Gils, A., Declerck, P. J. and Bieth, J. G. (2005) The conversion of active to latent plasminogen activator inhibitor-1 is an energetically silent event. Biophys. J. 88, 2848-2854

43 de Bentzmann, S., Polette, M., Zahm, J. M., Hinnrasky, J., Kileztky, C., Bajolet, O., Klossek, J. M., Filloux, A., Lazdunski, A. and Puchelle, E. (2000) Pseudomonas aeruginosa virulence factors delay airway epithelial wound repair by altering the actin cytoskeleton and inducing overactivation of epithelial matrix metalloproteinase-2. Lab. Invest. 80, 209-219

44 Nagano, T., Hao, J. L., Nakamura, M., Kumagai, N., Abe, M., Nakazawa, T. and Nishida, T. (2001) Stimulatory effect of pseudomonal elastase on collagen degradation by cultured keratocytes. Invest. Ophthalmol. Vis. Sci. 42, 1247-1253

45 Urano, T., Ihara, H., Umemura, K., Suzuki, Y., Oike, M., Akita, S., Tsukamoto, Y., Suzuki, I. and Takada, A. (2001) The profibrinolytic enzyme subtilisin NAT purified from Bacillus subtilis cleaves and inactivates plasminogen activator inhibitor type 1. J. Biol. Chem. 276, 24690-24696

46 Kunert, A., Losse, J., Gruszin, C., Huhn, M., Kaendler, K., Mikkat, S., Volke, D., Hoffmann, R., Jokiranta, T. S., Seeberger, H., Moellmann, U., Hellwage, J. and Zipfel, P. F. (2007) Immune evasion of the human pathogen Pseudomonas aeruginosa: elongation factor Tuf is a factor $\mathrm{H}$ and plasminogen binding protein. J. Immunol. 179, 2979-2988

47 Ullberg, M., Kronvall, G., Karlsson, I. and Wiman, B. (1990) Receptors for human plasminogen on Gram-negative bacteria. Infect. Immun. 58, 21-25

48 Chavakis, T., Athanasopoulos, A., Rhee, J. S., Orlova, V., Schmidt-Woll, T., Bierhaus, A., May, A. E., Celik, I., Nawroth, P. P. and Preissner, K. T. (2005) Angiostatin is a novel anti-inflammatory factor by inhibiting leukocyte recruitment. Blood. 105, 1036-1043

49 Hart, D. A. and Woods, D. E. (1994) Human urokinase, a serine proteinase, potentiates the in vitro growth of micro-organisms which commonly infect burn patients. J. Med. Microbiol. 41, 264-271

50 Heys, S. J., Orton, S. L. and Allison, D. G. (1999) Effect of urokinase on the extracellular virulence properties of Pseudomonas aeruginosa and Burkholderia cepacia. J. Basic Microbiol. 39, 17-24 
51 Appella, E., Robinson, E. A., Ullrich, S. J., Stoppelli, M. P., Corti, A., Cassani, G. and Blasi, F. (1987) The receptor-binding sequence of urokinase. A biological function for the growth-factor module of proteases. J. Biol. Chem. 262, 4437-4440

52 Smith, L., Rose, B., Tingpej, P., Zhu, H., Conibear, T., Manos, J., Bye, P., Elkins, M., Willcox, M., Bell, S., Wainwright, C. and Harbour, C. (2006) Protease IV production in Pseudomonas aeruginosa from the lungs of adults with cystic fibrosis. J. Med. Microbiol. 55, 1641-1644

53 Bode, W. and Huber, R. (1976) Induction of the bovine trypsinogen-trypsin transition by peptides sequentially similar to the N-terminus of trypsin. FEBS Lett. 68, 231-236

54 Comellas-Bigler, M., Maskos, K., Huber, R., Oyama, H., Oda, K. and Bode, W. (2004) 1.2 A crystal structure of the serine carboxyl proteinase pro-kumamolisin; structure of an intact pro-subtilase. Structure. 12, 1313-1323 
TABLES

Table 1. Cleavage sites for LasB and PIV within components of the human Plg activation system

\begin{tabular}{|c|c|c|}
\hline Substrate & $\begin{array}{c}\text { Peptide bonds cleaved } \\
\text { by LasB }\end{array}$ & $\begin{array}{c}\text { Peptide bonds cleaved } \\
\text { by PIV }\end{array}$ \\
\hline pro-uPA & $\begin{array}{l}\mathrm{PRFK}^{158}-{ }^{159} \mathbf{I I G G}^{(a)} \\
\mathrm{SNKY}^{24}-{ }^{25} \mathbf{F S N I}\end{array}$ & $\begin{array}{l}\mathrm{PRFK}^{158}-{ }^{159} \mathrm{IIGG}^{(\mathrm{a})} \\
\mathrm{VSNK}^{23}-{ }^{24} \mathrm{YFSN}^{(a)}\end{array}$ \\
\hline Plg & $\begin{array}{l}\text { TEAS }^{441}-{ }^{442} V_{V A P}^{(a)} \\
\text { EASV }^{442}-{ }^{443} V^{(a)}\end{array}$ & \\
\hline UPAR & $\begin{array}{l}\text { SGRA }^{84}-{ }^{85} \mathbf{V T Y S}^{(\mathrm{b})} \\
\mathrm{RAVT}^{86}-{ }^{87} \mathbf{Y S R S}^{(\mathrm{b})} \\
\mathrm{LDVQ}^{279}-{ }^{280} \mathbf{Y R S G}^{(\mathrm{b})}\end{array}$ & none \\
\hline pro-MMP-2 & $\operatorname{DVAN}^{80}-{ }^{81} \mathbf{Y N F F}^{(\mathrm{c})}$ & none \\
\hline
\end{tabular}

(a): peptide bonds hydrolyzed by LasB and/or PIV were identified by aminoterminal microsequencing, as described in the Experimental section;

(b): according to [32];

(c): according to the known activation cleavage site within human pro-MMP-2 (www.uniprot.org);

none: no cleavage observed.

Preferred amino acids in the P1 (for PIV) and P1' (for LasB) position of the cleavage site are set in bold. 


\section{FIGURE LEGENDS}

Figure 1: Activation of human pro-urokinase by purified LasB, or by the secretomes of $P$. aeruginosa LasB-expressing or LasB-deficient strains of $\boldsymbol{P}$. aeruginosa.

Purified human pro-uPA (200 ng, $\approx 450 \mathrm{nM}$ ) was left untreated (NT), exposed to its canonical activator plasmin $(\mathrm{Pm}, 45 \mathrm{nM})$, to increasing concentrations of purified LasB $(A, B)$, or to increasing quantities (expressed as a percentage of the final volume of the reaction mixture) of the secretome either from the LasB-expressing pseudomonal strain PAO1 (PAO1-Sec; $C$, $D$ ) or from the isogenic, LasB-deficient strain PDO240 (PDO240-Sec; E,F), for $60 \mathrm{~min}$ at $37^{\circ} \mathrm{C}$. $(A, C, E)$ Proteins were analyzed by immunoblotting using a chicken anti-uPA pAb (dilution 1/2,000), as described in the Material and Methods section. Portions of the films corresponding to the location of the relevant molecular species, located by an arrow on the left-hand side, are shown and their apparent molecular mass $(\mathrm{Mr} r)$ is indicated on the righthand side. One out of three analyses showing similar results is illustrated. $(B, D, F)$ In parallel, uPA activity was assayed towards a selective chromogenic substrate (Pefachrome uPA). The proteolytic activity of $200 \mathrm{ng}$ of purified uPA was used as an external positive control and corresponds to $100 \%$ activation of the zymogen present in the assay. Histograms represent mean + SEM of 3 independent experiments. Note that pro-uPA, LasB and the PAO1-Sec and PDO240-Sec per se have no or minimal activity on Pefachrome uPA.

Figure 2: Activation of human pro-urokinase by a benzamidine-sensitive secreted pseudomonal protease.

Pro-uPA was either left untreated (NT), or exposed to $1 \%(\mathrm{v} / \mathrm{v})$ of PDO240-Sec $(A)$, to $1 \%$ $(\mathrm{v} / \mathrm{v})$ PAO1-Sec $(B$, left-hand panel), or to $100 \mathrm{nM}$ LasB ( $B$, right-hand panel), for $60 \mathrm{~min}$ at $37^{\circ} \mathrm{C}$, in the presence or absence of the following protease inhibitors: orthophenanthroline (OPA, $10 \mathrm{mM}$ ), benzamidine (Benz., $5 \mathrm{mM}$ ), E64 $(10 \mu \mathrm{M})$ or pepstatin A (Pep., $5 \mu \mathrm{M})$, which were either added alone, or in combination (Mix, combination of all four inhibitors). Pro-uPA activation was then evaluated by immunoblotting $(n=3)$, as described in the legend to Fig. 1 .

\section{Figure 3: Production of recombinant active pseudomonal PIV.}

(A) Schematic structure comparison of the natural and E. coli-expressed PIV proteins (upper and lower panels, respectively). (B,C) Preparations of E. coli-expressed PIV, or uPAR-D1 (used as a control, nonprotease recombinant protein preparation), either purified or purified and refolded, were analyzed by SDS-PAGE under reducing conditions followed by transfer onto a PVDF membrane and Coomassie blue staining $(B)$, or immunoblotting using an antiHis $\mathrm{mAb}$ (PentaHis, $1 \mu \mathrm{g} / \mathrm{ml}, C)$. $(D, E)$ Refolded recombinant PIV and uPAR-D1 preparations were evaluated for peptidase $(D)$ and proteinase $(E)$ activity, using the chromogenic substrate Chromozym PL, or gelatin zymography, respectively, as detailed in the Experimental section. For zymography, a reference gelatinolyc profile was provided by the bacterial secretomes originating from the pseudomonal PAO1 and PDO240 strains. Results obtained for PIV and uPAR-D1 batches representative of 2 to 3 independent preparations are illustrated.

Figure 4: Activation of human pro-urokinase by recombinant pseudomonal PIV.

Pro-uPA was either left untreated (NT), or exposed to Pm, to increasing concentrations of recombinant PIV (rPIV, 7.5-200 nM), to recombinant uPAR-D1 $(200 \mathrm{nM})$, or to native PIV (nPIV, $100 \mathrm{nM}$ ), for $60 \mathrm{~min}$ at $37^{\circ} \mathrm{C}$. Immunoblot analysis for pro-uPA processing $(A$, representative of 2 experiments) and measurement of uPA activity $(B$, mean + SEM, n=4) were then performed exactly as described in the legend to Fig.1. Note that pro-uPA, rPIV, uPAR-D1 or nPIV per se, have no appreciable direct activity on the uPA substrate. 


\section{Figure 5: Processing of components of the human Plg activation system by pseudomonal} proteases.

Human Plg $(\approx 200 \mathrm{nM})$, recombinant human uPAR $(\approx 20 \mathrm{nM})$, recombinant human PAI-1 $(\approx$ $20 \mathrm{nM}$ ), or fibroblast-derived culture medium containing pro-MMP-2 were either left untreated (NT), or exposed to pseudomonal proteases, either pure, or as they are expressed within the PAO1-Sec or the PDO240-Sec, as indicated in the legends to Fig. 1 and 4. (A) The proteolytic processing of Plg was analyzed by SDS-PAGE (1 $\mu \mathrm{g}$ Plg per lane) followed by Coomassie blue staining. $(B, C)$ uPAR and PAI-1 processing were evaluated by immunoblot (10 ng protein per lane) using an anti-uPAR mAb directed against the $\mathrm{D} 2$ domain (\#3932, $0.05 \mu \mathrm{g} / \mathrm{ml})(B)$ or an anti-PAI-1 mAb recognizing the seuquence 24-158 of human PAI-1 (C9, $0.4 \mu \mathrm{g} / \mathrm{ml})(C)$. (D) (Pro-)MMP-2 activity was detected by gelatin zymography $(20 \mu \mathrm{l}$ of reaction mixture per lane), with the gelatinolytic profiles of the bacterial secretomes depicted in the right-hand panel. Note that the alkaline protease/AprA activity is higher in the PDO240-Sec as compared to the PAO1-Sec. Results illustrated are representative of 2 to 3 independent experiments. 
Biochemical Journal Immediate Publication. Published on 25 Mar 2010 as manuscript BJ20091806

A

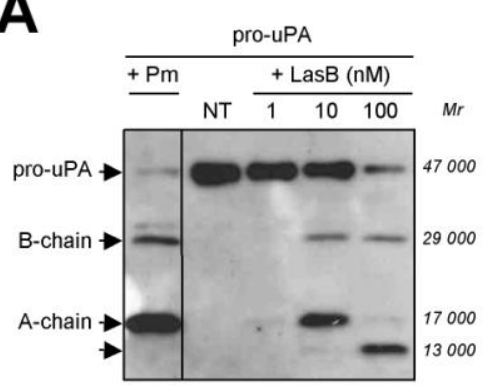

B

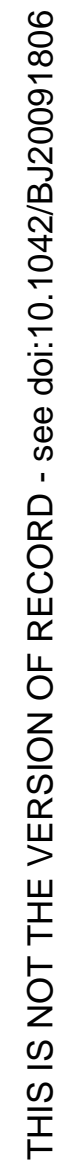

C

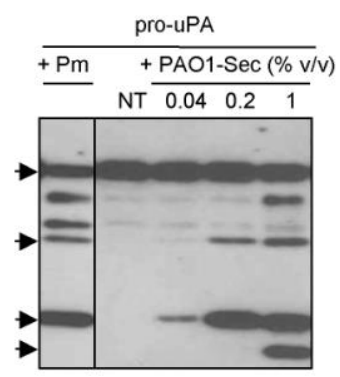

D

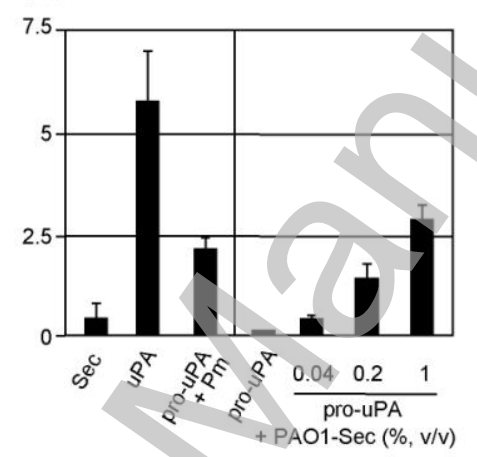

E

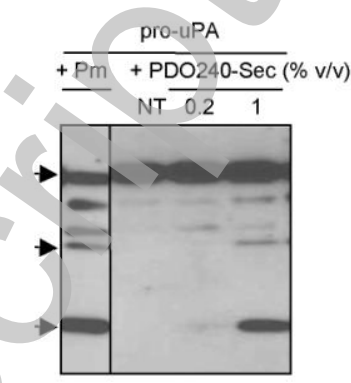

$\mathbf{F}$

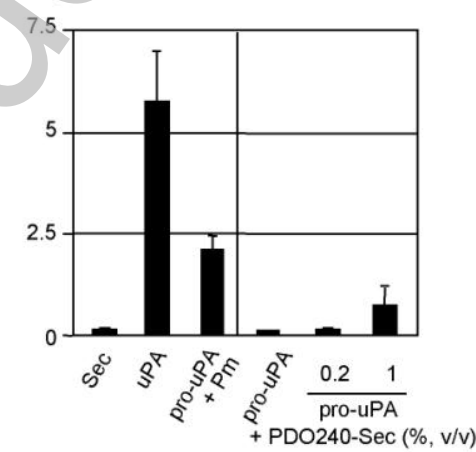

Fig. 1

Licenced copy. Copying is not permitted, except with prior permission and as allowed by law. (C) 2010 The Authors Journal compilation (c) 2010 Portland Press Limited 

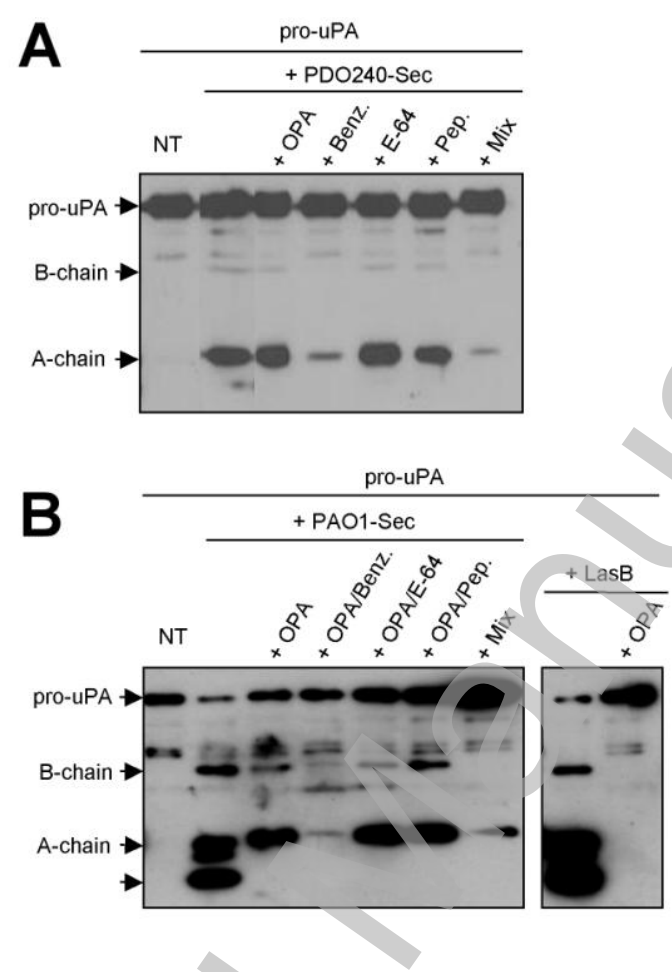

Fig. 2 
B Biochemical Journal Immediate Publication. Published on 25 Mar 2010 as manuscript BJ20091806

A
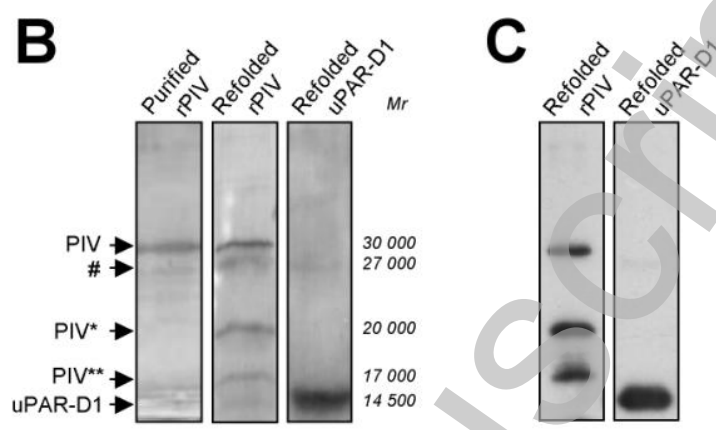

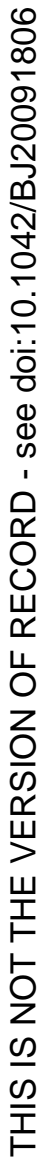
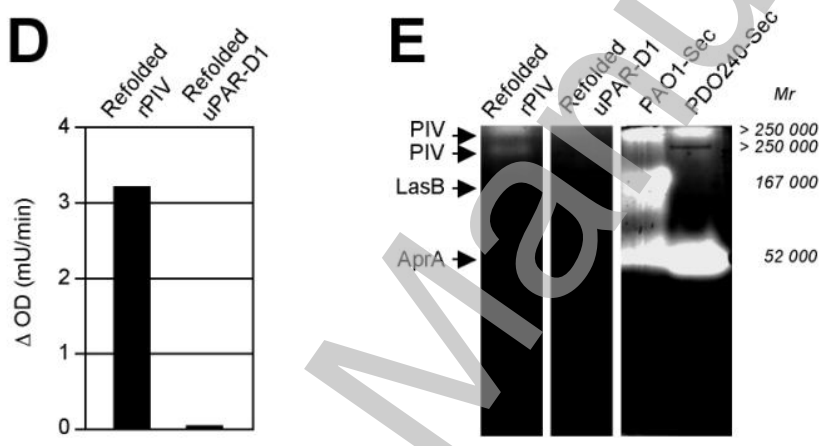

Fig. 3 


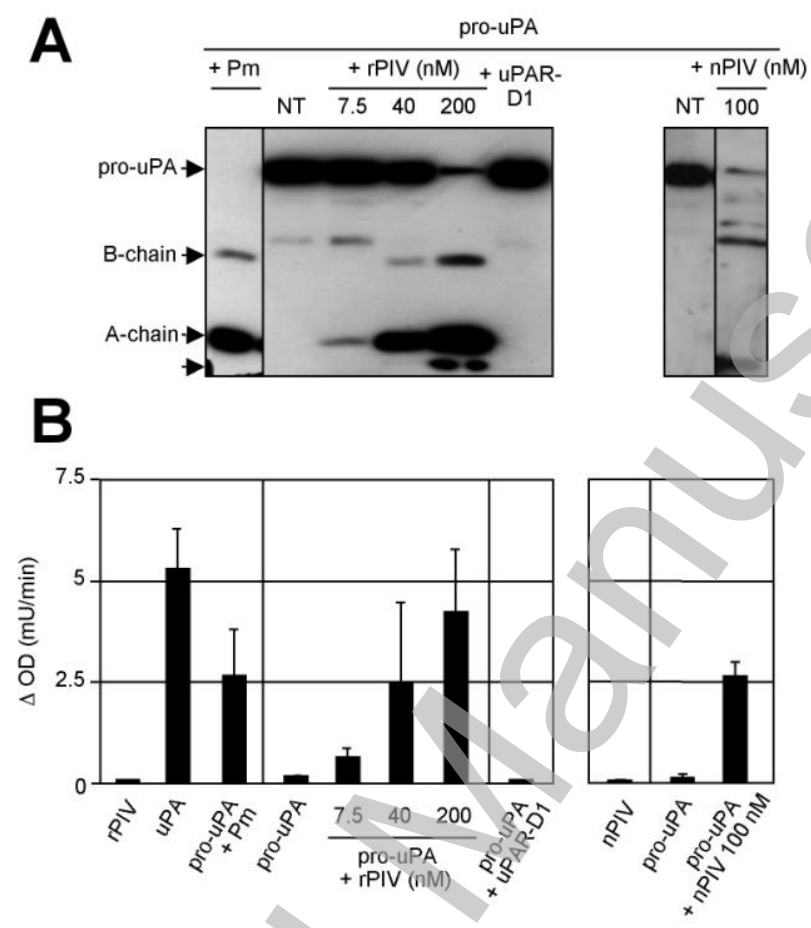

Fig. 4 
Biochemical Journal Immediate Publication. Published on 25 Mar 2010 as manuscript BJ20091806

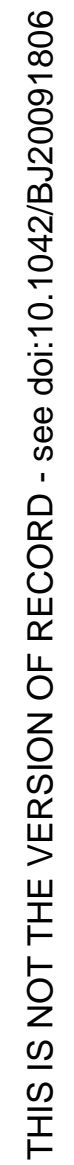
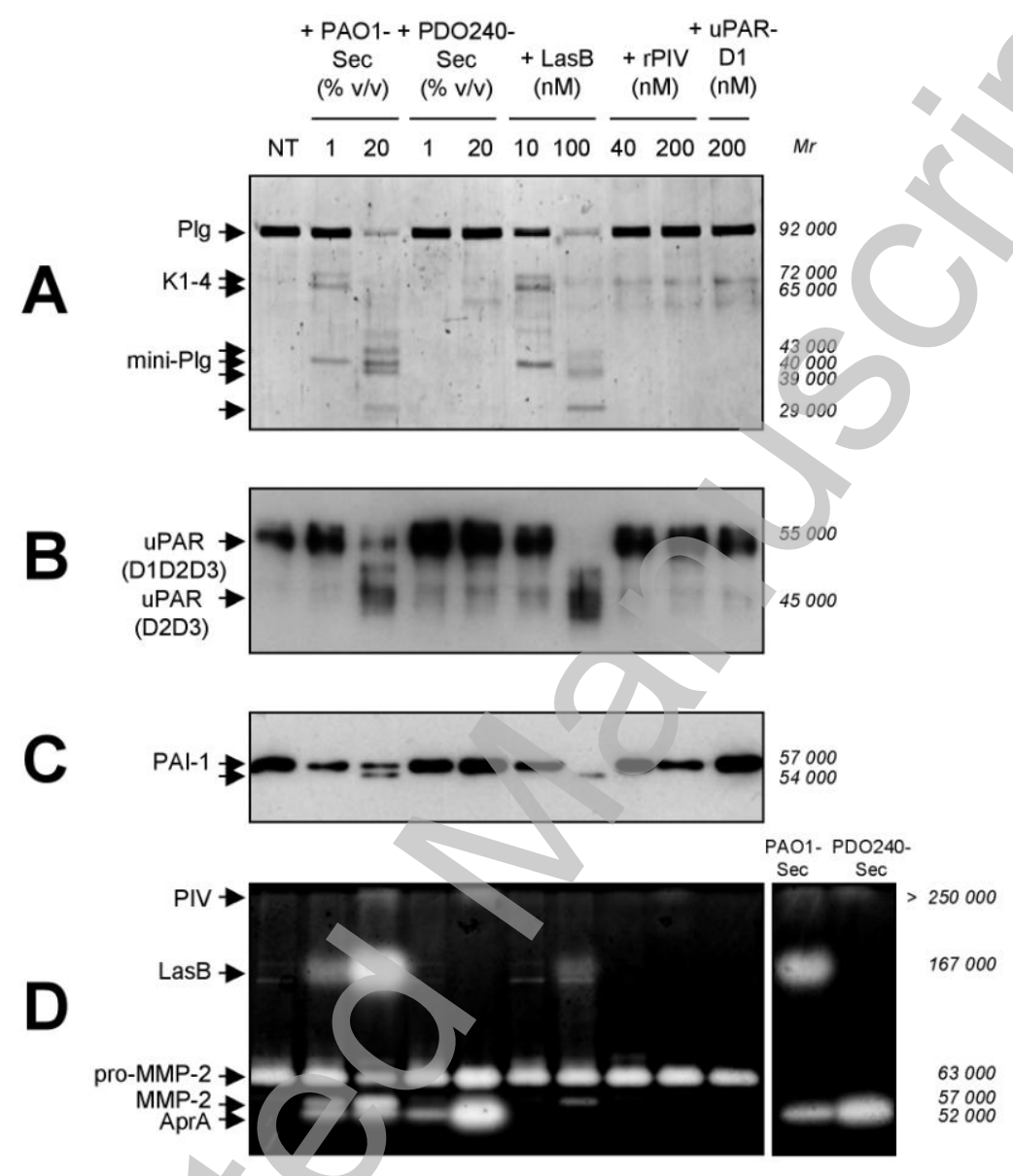

Fig. 5

Licenced copy. Copying is not permitted, except with prior permission and as allowed by law. (C) 2010 The Authors Journal compilation (c) 2010 Portland Press Limited 